\title{
NGS study of glucocorticoid response genes in inflammatory bowel disease patients
}

\author{
Marzena Skrzypczak-Zielinska1, Marcin Gabryel², Daria Marszalek ${ }^{1}$, Agnieszka Dobrowolska², \\ Ryszard Slomski ${ }^{1}$
}

\begin{abstract}
${ }^{1}$ Institute of Human Genetics, Polish Academy of Sciences, Poznan, Poland ${ }^{2}$ Department of Gastroenterology, Dietetics and Internal Diseases, Poznan University of Medical Sciences, Poznan, Poland
\end{abstract}

Submitted: 18 December 2018; Accepted: 3 April 2019;

Online publication: 5 May 2019

Arch Med Sci 2021; 17 (2): 417-433

DOI: https://doi.org/10.5114/aoms.2019.84470

Copyright @ 2019 Termedia \& Banach

\section{Abstract}

Introduction: Despite intensive research and a long history of glucocorticoids being applied in various clinical areas, they still generate a challenge for personalized medicine by causing resistance or dependence in nearly $50 \%$ of patients treated. The objective of the present study was to determine the genetic predictors of variable reactions in inflammatory bowel disease patients to glucocorticoid therapy. Therefore, based on the current knowledge on how glucocorticoids act, we have compiled a panel of 21 genes for variant analysis: NR3C1, NLRP1, IPO13, FKBP5, HSPA4, ABCB1, STIP1, HSP90AA1, IL-1A, IL-1B, IL-2, IL-4, CXCL8, IL-10, NFKBIA, JUN, MIF, TNF, MAPK14, CYP3A4, and CYP3A5.

Material and methods: These genes were analyzed using the amplicon next-generation sequencing method in a group of 139 diagnosed and clinically characterized inflammatory bowel disease patients with a confirmed glucocorticoid response.

Results: Analysis of all the targeted DNA sequences for the whole patient group indicated 121 different functional variants. After association analyses of 31 selected variants, the polymorphism c.1088A>G in the NR3C1 gene was linked with glucocorticoid resistance $(p=0.002)$, variant $c .241+6 \mathrm{~A}>\mathrm{G}$ of the FKBP5 gene with glucocorticoid sensitivity $(p=0.040)$, and deletion c.306-7delT in the MAPK 14 gene with an adverse therapeutic effect (dependency and resistance, $p=0.041$ ) in ulcerative colitis patients. In Crohn's disease, the change c.2685+49T>C of the $A B C B 1$ gene related to glucocorticoid resistance $(p=0.034)$.

Conclusions: Among the 21 analyzed genes, four (NR3C1, FKBP5, MAPK14, and $A B C B 1$ ) revealed a significant impact on the glucocorticoid treatment response, which could result in valuable pharmacogenetic biomarkers after being confirmed in other populations and in functional studies.

Key words: glucocorticosteroids, gene polymorphism, pharmacogenetics, inflammatory bowel disease, next-generation sequencing.

\section{Introduction}

Crohn's disease (CD) and ulcerative colitis (UC) are inflammatory disorders of the gastrointestinal tract known as inflammatory bowel disease (IBD). In UC the inflammation involves the distal intestine and ileum, and in $C D$ it can affect the whole region of the digestive tract. The development of IBD with advanced symptoms frequently begins at the age of

\author{
Corresponding author: \\ Marzena Skrzypczak- \\ Zielinska PhD \\ Institute \\ of Human Genetics \\ Polish Academy \\ of Sciences \\ 32 Strzeszynska St \\ 60-479 Poznan, Poland \\ Phone: +48 502459904 \\ E-mail: \\ mskrzypczakzielinska@gmail. \\ com
}


20-30, and due to the chronic nature of the disorder, patients require long-term treatment, usually for their whole life [1, 2]. Synthetic glucocorticosteroids (GCs) are among the most commonly used first-line conventional drugs, dedicated to remission induction in IBD patients with mild and severe exacerbations [3]. The GCs are widely known for their rapid anti-inflammatory and immunomodulatory effect, which is followed by binding the intracellular GC receptor (GR) and potent inhibition of $\mathrm{T}$ cell activation and cytokine secretion. Effective suppression of inflammatory gene expression occurs through several distinct mechanisms $[4,5]$. However, not all patients show a positive response to GC therapy. On average, only every second adult patient with IBD is sensitive to GCs, close to $20 \%$ of subjects are GC resistant, and approximately $30-40 \%$ of patients become dependent on these drugs [6]. Personalized medicine could be very promising in CD and UC therapy outcome, but except for thiopurine drugs with pharmacogenetics dosing guidelines, we do not have genetic biomarkers for IBD treatment [7, 8].

Although the reason for the differential response is multifactorial, including disease severity and complications, as well as environmental factors, it can be expected that the genetic component plays the most crucial role, which is estimated at up to $95 \%[9,10]$. To date, most pharmacogenetic research on GCs has indicated the NR3C1 gene coding for the GCs receptor $(G R)$ protein and the $A B C B 1$ gene responsible for synthesis of the multidrug resistance protein 1 a membrane GC efflux transporter whose overexpression results in decreased cytoplasmic GC concentration [11, 12]. Fewer $G C$ response studies also concern the participation of the FKBP5, TNF, and NLRP1 genes coding for co-chaperone $51 \mathrm{kDa}$ FK506-binding protein (FKBP-51), tumor necrosis factor (TNF) and NACHT, LRR and PYD domain-containing protein 1, respectively [13-16]. However, more molecules are engaged in GCs' mechanism of action, whose polymorphism could relate to inter-individual differences observed in drug efficacy and side effects. These include: 1) genes coding for a GR cellular protein complex consisting of chaperone heat shock protein HSP 90- $\alpha$ and HSP $70 \mathrm{kDa}$, co-chaperones, including stress-induced-phosphoprotein 1 (STI1) and the immunophilin FKBP-51, which bind, stabilize and organize hormone-free GR in the cytosol; 2) factors involved in the hormonal control of target gene transcription in the nucleus, i.e., transcription factor AP-1,

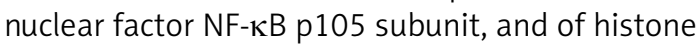
acetylation, as well as chromatin remodeling, 3) principal effectors of GCs, e.g. cytokines and their regulators: tumor necrosis factor (TNF), interleukin-1 $\beta$ (IL-1 $\beta$ ), interleukin-2 (IL-2), interleukin-8
(IL-8) $[4,6,17]$. Polymorphisms in genes involved in the nuclear transport factors (importin IPO13) or in the metabolism of these hormones, i.e. cytochromes P450 (CYP3A4, CYP3A5), have also been suggested as other possible candidates of GC response modulators [11]. On the one hand, science emphasizes the role of genetics in predicting GCs' clinical reactions and on the other hand, practice indicates the need of personalized medicine for improving the GC efficacy and safety rates [9, 13].

In this study, we aimed to determine the genetic predictors of GCs' clinical response within a selected group of 21 genes coding for GR and their complex proteins, transcription factors, GC target genes, GC biotransformation enzymes and GC transporters in a group of 139 diagnosed and clinically characterized Polish IBD patients with a confirmed glucocorticoid response. The goal of these investigations is to better understand diverse patient reactions to GCs and risk factors. Our findings, which identify potential new variants associated with $\mathrm{GC}$ reactions, provide the basis for further research, including therapy in different diseases, various populations, and functional studies. In this work, we focused on the relationship between altered $G C$ response and functional variants of the following genes: NR3C1, NLRP1, IPO13, FKBP5, HSPA4, ABCB1, STIP1, HSP9OAA1, IL-1A, IL-1B, IL-2, IL-4, CXCL8, IL-10, NFKBIA, JUN, MIF, TNF, MAPK14, CYP3A4, and CYP3A5. A novel method, based on next-generation sequencing (NGS) of amplicon libraries, was developed for the purpose of analysis of candidate genes in the current study.

\section{Material and methods}

\section{Patients and samples}

One hundred and thirty-nine Polish patients with IBD hospitalized in the Department of Gastroenterology, Dietetics and Internal Medicine, Poznan University of Medical Sciences (Poland) were enrolled in this study between May 2013 and February 2018. This group included 77 (55.4\%) individuals with Crohn's disease (CD) and 62 (44.6\%) individuals with ulcerative colitis (UC). All of them were of Caucasian ancestry. The characteristics of the patients are shown in Table I [18]. In addition to the response to GC treatment defined in all patients, in over half of the study group (51.1\%) side effects were observed, including weakening, osteoporosis/osteopenia, peptic ulcers, stretch marks, acne, difficult wound healing, petechiae, edema, hypertension, thrombosis, infection, headache, glucose metabolism disorder, cataract, glaucoma, mental disorders, and increased weight and appetite.

The inclusion criteria were as follows: 1) age over 18 years; 2) diagnosis of IBD based on clin- 
Table I. Clinical characteristics of patients included in the study

\begin{tabular}{|c|c|c|c|c|}
\hline Parameter & $\begin{array}{c}\text { Total patients } \\
(n=139)\end{array}$ & $\begin{array}{l}\text { GC-sensitive } \\
(n=77)^{\#}\end{array}$ & $\begin{array}{l}\text { GC-dependent } \\
(n=38)^{\#}\end{array}$ & $\begin{array}{c}\text { GC-resistant } \\
(n=24)^{\#}\end{array}$ \\
\hline Age at study, mean \pm SD & $36.07 \pm 14.08$ & $38.2 \pm 15.63$ & $36.5 \pm 15.61$ & $33.5 \pm 10.29$ \\
\hline Age at diagnosis, mean \pm SD & $31.3 \pm 14.31$ & $32.5 \pm 14.94$ & $30.5 \pm 14.02$ & $30.5 \pm 14.02$ \\
\hline \multicolumn{5}{|l|}{ Sex, $n(\%):$} \\
\hline Female & $58(41.7)$ & $31(40.3)$ & $17(44.7)$ & $10(41.7)$ \\
\hline Male & $81(58.3)$ & $46(59.7)$ & $21(55.3)$ & $14(58.3)$ \\
\hline \multicolumn{5}{|l|}{ Diagnosis, $n(\%):$} \\
\hline$C D$ & $77(55.4)$ & $40(52.0)$ & $26(68.4)$ & $11(45.8)$ \\
\hline UC & $62(44.6)$ & $37(48.0)$ & $12(31.6)$ & $13(54.2)$ \\
\hline \multicolumn{5}{|l|}{ Disease severity, $n(\%)$ : } \\
\hline Mild & $8(5.8)$ & $4(5.2)$ & $1(2.6)$ & $3(12.5)$ \\
\hline Moderate & $72(51.8)$ & $42(54.5)$ & $25(65.8)$ & $5(20.8)$ \\
\hline Severe & $59(42.4)$ & $31(40.3)$ & $12(31.6)$ & $16(66.7)$ \\
\hline \multicolumn{5}{|l|}{ Intestinal location*, $n$ (\%): } \\
\hline L1, ileal & $24(17.3)$ & $13(16.9)$ & $8(21.1)$ & $3(12.5)$ \\
\hline L2, colonic & $9(6.5)$ & $4(5.2)$ & $5(13.2)$ & $0(0.0)$ \\
\hline L3, ileocolonic & $44(31.7)$ & $24(31.2)$ & $13(34.2)$ & $7(29.2)$ \\
\hline E1, proctitis & $5(3.6)$ & $4(5.2)$ & $1(2.6)$ & $0(0.0)$ \\
\hline E2, left-side & $10(7.1)$ & $8(10.4)$ & $2(5.2)$ & $0(0.0)$ \\
\hline E3, pancolitis & $47(33.8)$ & $24(31.2)$ & $9(23.7)$ & $14(58.3)$ \\
\hline Side effects occurrence of GCs, $n(\%)$ & $71(51.1)$ & $31(40.3)$ & $25(65.8)$ & $15(62.5)$ \\
\hline
\end{tabular}

"According to response classification as detailed in 'Material and Methods, Patients and samples' description. "Disease location was determined according to the Montreal classification [18]. GC - glucocorticoid, SD - standard deviation, CD - Crohn's disease, UC-ulcerative colitis, $n$ - number.

ical symptoms, endoscopy with histopathological confirmation (Figure 1), radiological images, and laboratory tests (including complete blood count with smear, hematocrit, erythrocyte sedimentation rate, C-reactive protein, iron, ferritin); 3) disease duration over 6 months and 4) at least one episode of treatment with GCs. All individuals gave their written consent to genetic testing and evaluation of biochemical parameters in serum and colonoscopy. The study was approved by the Bioethical Committee of Poznan University of Medical Sciences under Resolution No. 436/13.

In all patients, the clinical data were obtained with a minimum of 1 year of continuous follow-up evaluation after the start of GC treatment. Some patients were evaluated retrospectively and the rest prospectively. The disease activity was determined according to the Crohn's Disease Activity Index (CDAI) for patients with CD and according to the Truelove-Witts score for patients with UC. GC therapy consisted mostly of methylprednisolone and hydrocortisone, and in rare cases, budesonide
(Table II). The dose of GCs (methylprednisolone and hydrocortisone) was converted to prednisolone using a corticosteroid conversion calculator (https://clincalc.com/corticosteroids/). According to the existing criteria of the European Crohn's and Colitis Organization (ECCO), the patients were assigned to one of three groups: 1) GC-sensitive, if after the initiation of treatment within a few days they achieved and maintained clinical remission; 2) GC-dependent, if the symptoms of exacerbation recurred after reducing the dose of GCS below $10 \mathrm{mg} / 24 \mathrm{~h}$ prednisolone or within 3 months after GCs were discontinued, 3) GC-resistant, if symptoms of exacerbation persisted despite 4 weeks of GC therapy in doses corresponding to a minimum of $0.75 \mathrm{mg} / \mathrm{kg}$ of prednisolone [1, 2]. The GCs were administered as a monotherapy or in combination therapy with 5-aminosalicylic acid preparations.

Moreover, in total 12 healthy subjects ( 6 women and 6 men) without drug treatment ranging in age from 21 to 54 years old were used in this study as controls in all molecular, biochemistry 

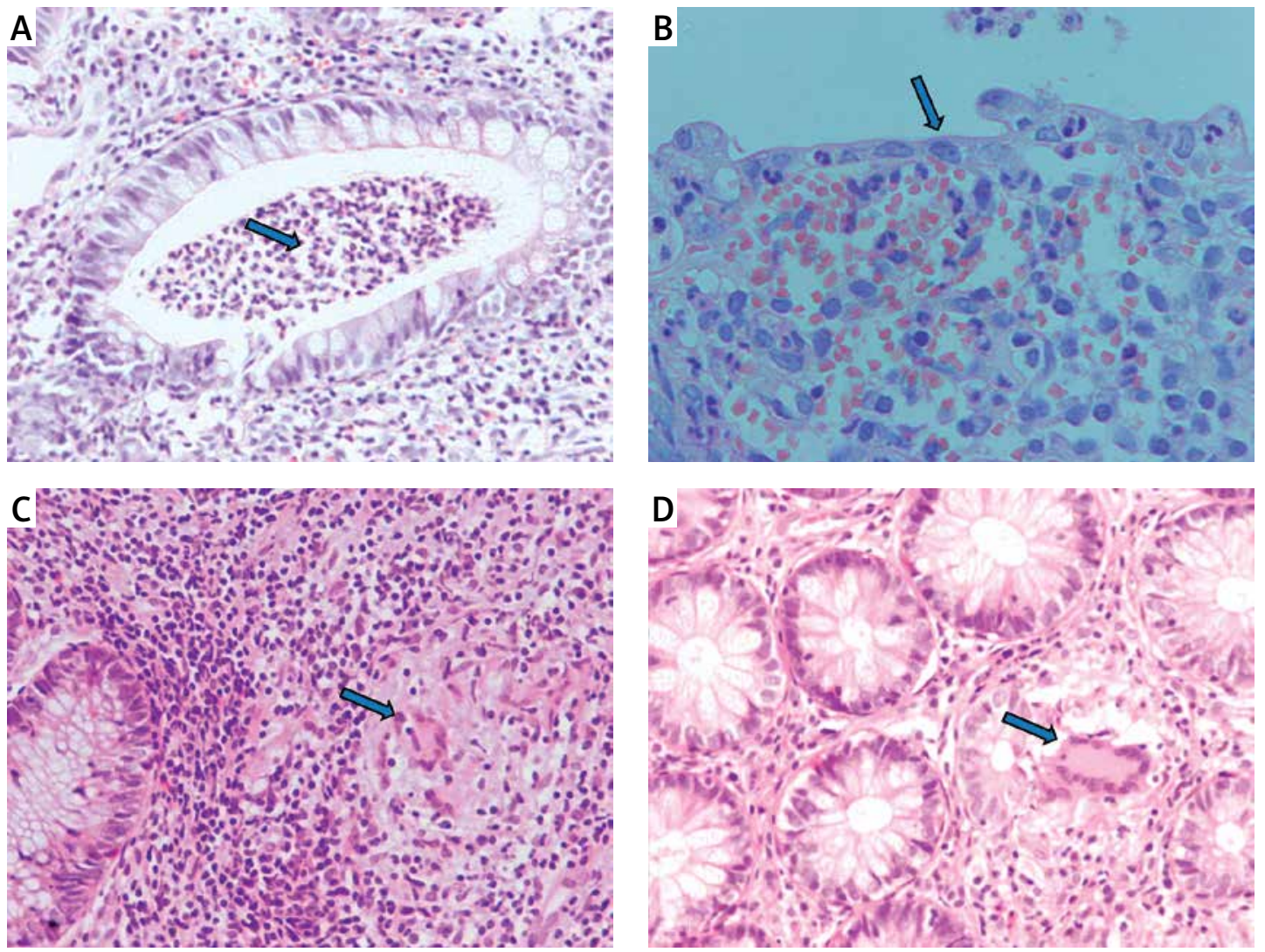

Figure 1. Histopathology of colon mucosa in IBD patients. Patient with UC: A - crypt abscess (blue arrow), B - thinned intestinal epithelium (blue arrow). Patient with CD: C, D - granulomas (blue arrows). Stain: hematoxylin and eosin, magnification 200× (A, C, D), 400× (B)

and immunohistochemistry methods. Exclusion criteria in the control group included chronic disease or any organ dysfunction, ongoing infections, excessive alcohol consumption, cigarette smoking and receiving any supplementation influencing hepatic and kidney enzymes.

\section{Long-range (LR)-PCR amplification}

Genomic DNA from all subjects was isolated from peripheral blood according to standard procedures using the method with guanidine isothiocyanate and stored at $4^{\circ} \mathrm{C}$ in a TE buffer containing $1.0 \mathrm{mM}$ EDTA and $10 \mathrm{mM}$ Tris-Cl until use. The amplification of the NR3C1, NLRP1, IPO13, FKBP5, HSPA4, ABCB1, STIP1, HSP9OAA1, IL-1A, IL-1B, IL-2, IL-4, CXCL8, IL-10, NFKBIA, JUN, MIF, TNF, MAPK 14, CYP3A4, and CYP3A5 genes was carried out using primers containing exons, splice junctions and promoters, as well as $5^{\prime}$ and $3^{\prime}$ flanking sequences (Table III). The LR-PCR conditions that were established are presented in Table IV. Primers were designed as part of this work using the NCBI (National Center for Biotechnology Information) Primer-BLAST tool in reference to the human genomic sequence (GRCh37/hg19). The only exceptions were the primers and amplification conditions for the $I L-1 B, T N F$ and $A B C B 1$ genes, which originated from our previous studies [19-21]. Due to the limitation of the LR-PCR method in the length of efficiently amplified DNA fragments, the LR-PCR of short genes such as IL-1A (11.48 kb), IL-1B (7.02 kb) and IL-2 (5.25 kb) was performed in one fragment, but the long genes, e.g. NR3C1 (123.76 kb), FKBP5 (115.35 kb) or ABCB1 (210.00 $\mathrm{kb}$ ), were divided into several fragments (from 2 to 6 parts, Table III). Therefore, the amplification of the DNA sequence of 21 genes generates 54 amplicons. The numbering of the amplified fra gments in Tables III and IV is identical (and also corresponds with the lane numbering in Figure 2).

The amplification effect was controlled by electrophoresis in a $0.6 \%$ agarose gel (Sigma). To identify the approximate size of amplified fragments, the $1 \mathrm{~kb}$ DNA Ladder (Solis Biodyne) was used.

\section{Library preparation, NGS and Sanger sequencing}

Fifty-four amplicons of each patient were pooled in equimolar ratios. According to the manufacturer's protocol, $1 \mathrm{ng}$ of the pooled DNA fragments was subjected to the Nextera XT procedure (Illumina) using the Nextera XT DNA Sample Preparation Kit (Illumina) and Nextera XT Index Kit (96) (Illumina). Finally, we obtained 139 both-side 
indexed DNA libraries ready for high-throughput sequencing. Normalization of all libraries was carried out with magnetic beads, according to the Nextera XT procedure. Sequencing on an Illumina MiSeq System was performed as paired-end targeted resequencing using MiSeq Reagent Kit v2 (300 cycles) (Illumina). To verify the variants which were detected, Sanger sequencing for random samples was performed on an Applied Biosystems 3500 Genetic Analyzer using the BigDye Terminator v3.1 Cycle Sequencing Kit. The NGS analyses described were performed for the IBD patient group. However, for comparative purposes of the sequencing data, the minor allele frequency for the European population (MAF EU) from the 1000 Genomes Project was also used.

\section{Bioinformatic and statistical analysis}

Secondary bioinformatic analysis of NGS reads generated was performed using MiSeq Reporter analysis software (Illumina), and the resulting variants were characterized and filtered using VariantStudio Software v 3.0 (Illumina), according to the pipeline in Figure 3. In the first step, the NGS results concerning the sequences of 21 genes analyzed were aligned to the human reference sequence (version GRCh37/hg19). Next, the SNVs (single nucleotide variants) were detected and named, and we applied filtering parameters (GQX - genotyping quality $\geq 30$, read depth $\geq 10$ and heterozygous read ratio $\geq 35 \%$ ) to select high-quality NGS results. The data obtained were filtered according to the potential consequence at the protein level and the frequency of the minor allele $\geq 2 \%$. Thirty-one polymorphic variants were subjected to statistical analysis. We correlated the genetic results with GC response, including the division into three groups - GC-sensitive (S), -dependent (D) and -resistant (R) - for which the abbreviations $S, D$, and $R$, respectively, were used. This analysis aimed to compare all three GC-response groups in terms of genotype distribution for each polymorphic variant. Moreover, regarding $\mathrm{GC}$ response, the patients were also divided into two groups in two combinations: 1) correct responsive (GC-sensitive) versus poorly responsive subjects (GC-dependent and GC-resistant) abbreviated as S vs. D + R; as well as 2) GC-resistant versus the rest of the patients (GC-sensitive and GC-dependent) abbreviated as S + D vs. R. Those combinations were necessary to determine the genetic factors responsible for GC sensitivity and related to GC resistance. The calculations were carried out for the whole group of 139 patients, and for diagnosis of CD and UC.

The concordance of genotype distribution was verified using the Hardy-Weinberg equilibrium (HWE). All correlation analyses between GC re-

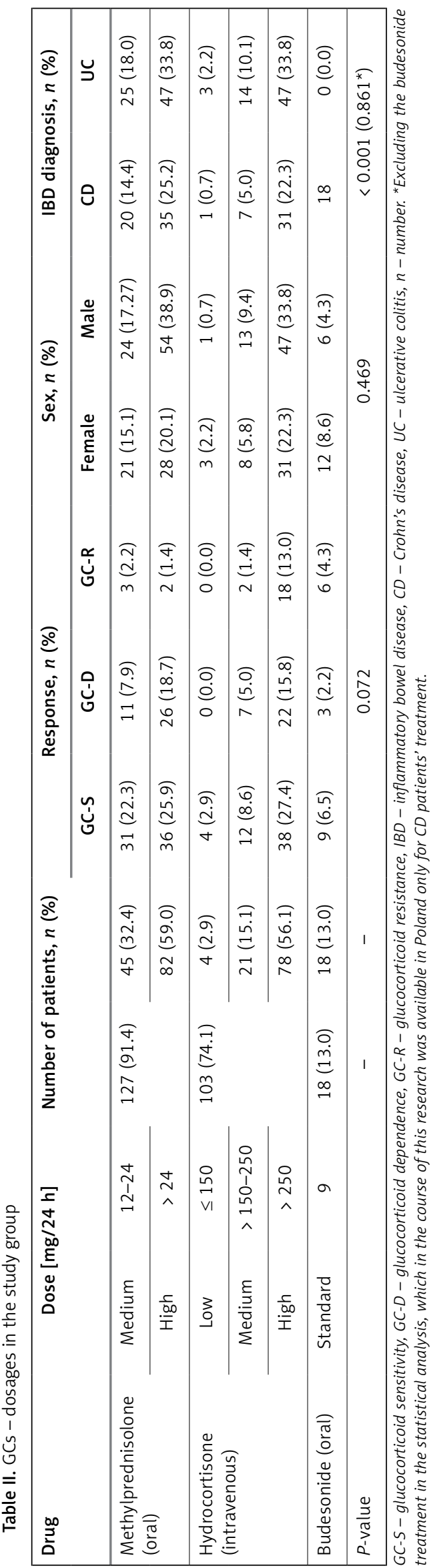



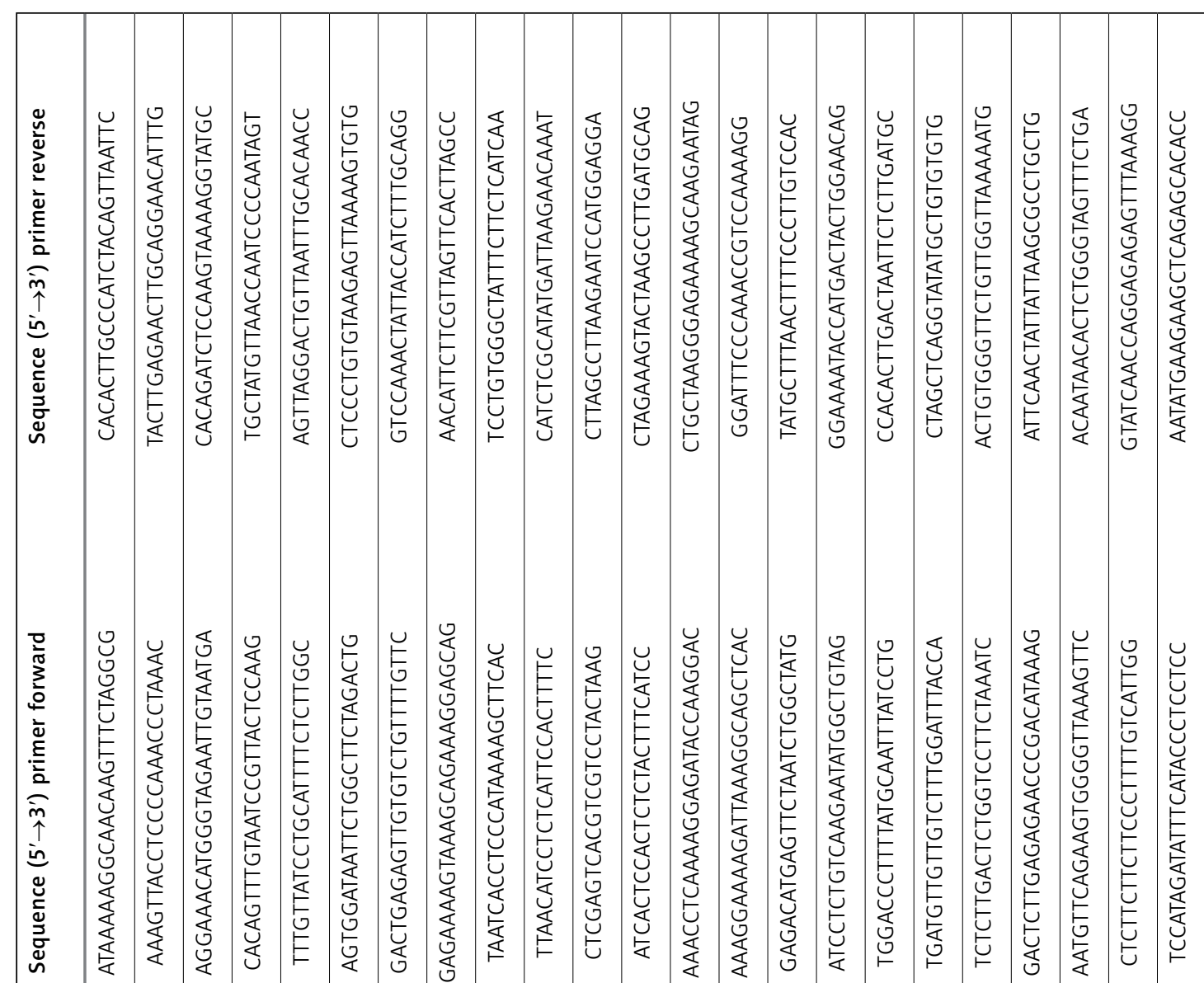

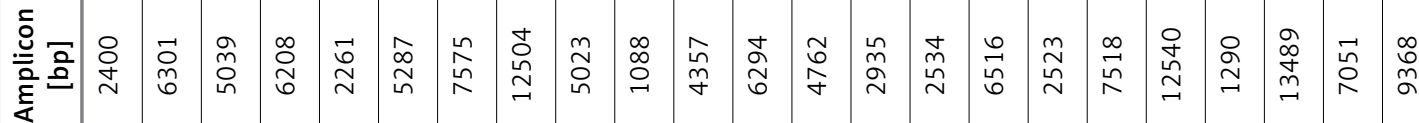

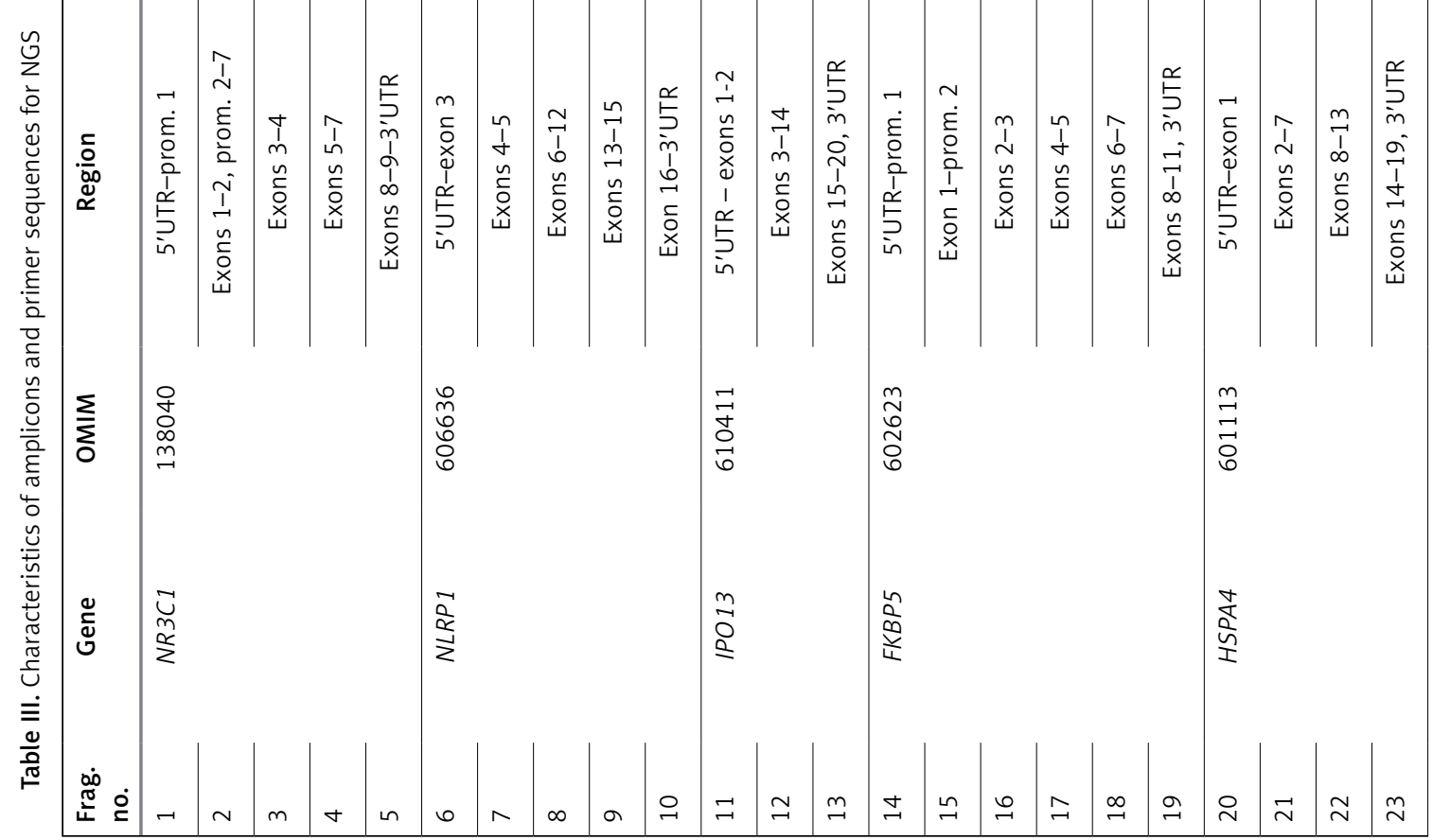



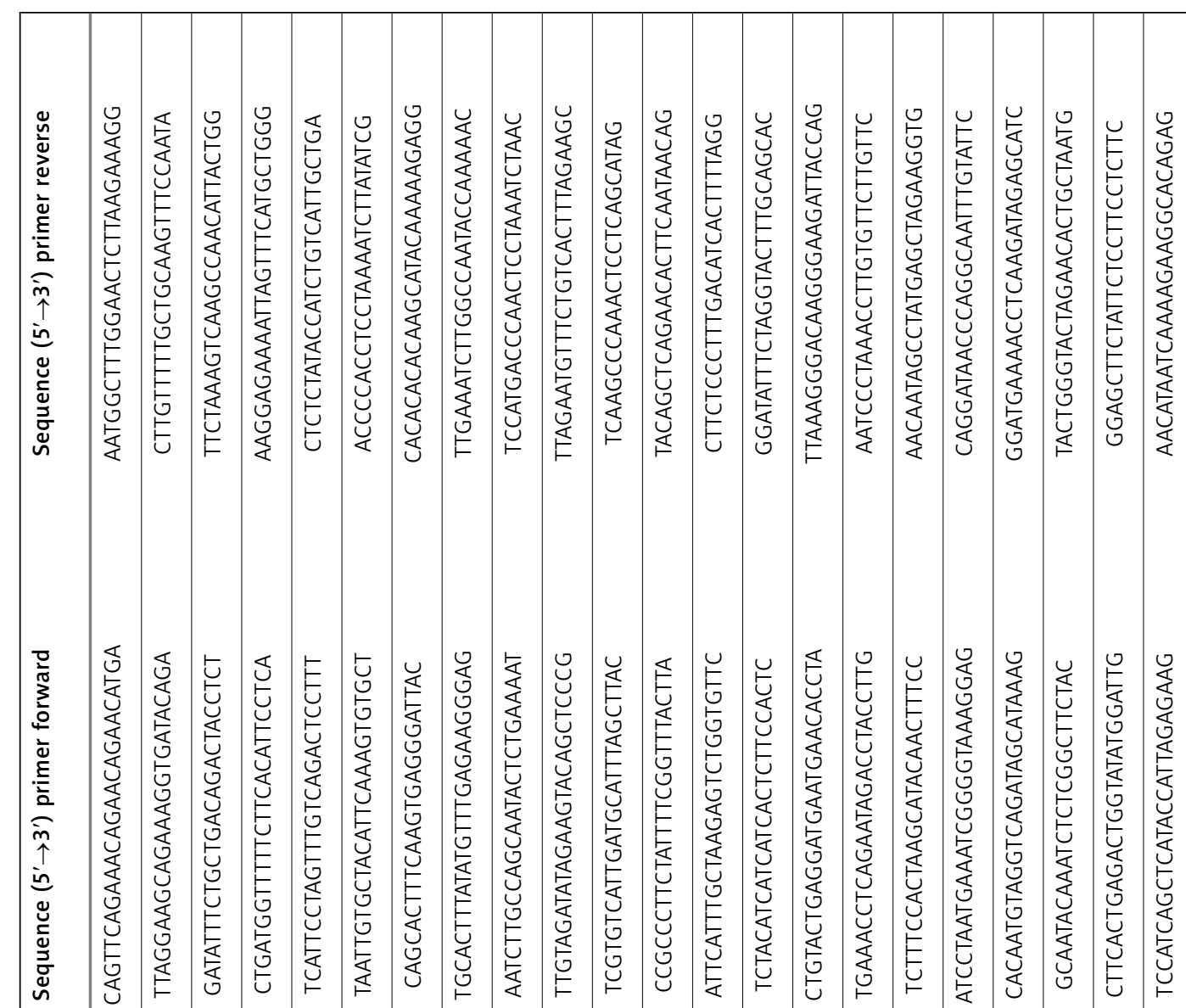

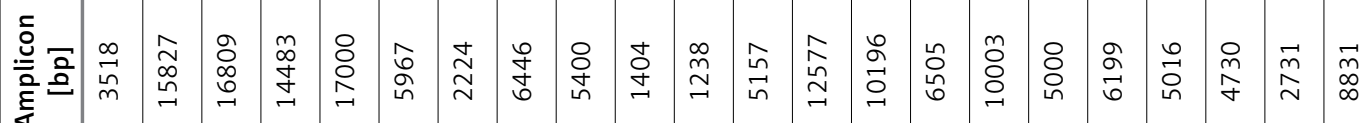

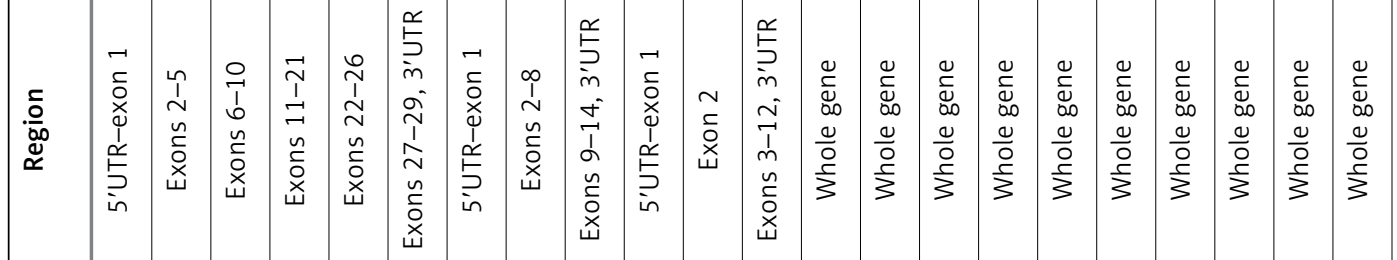

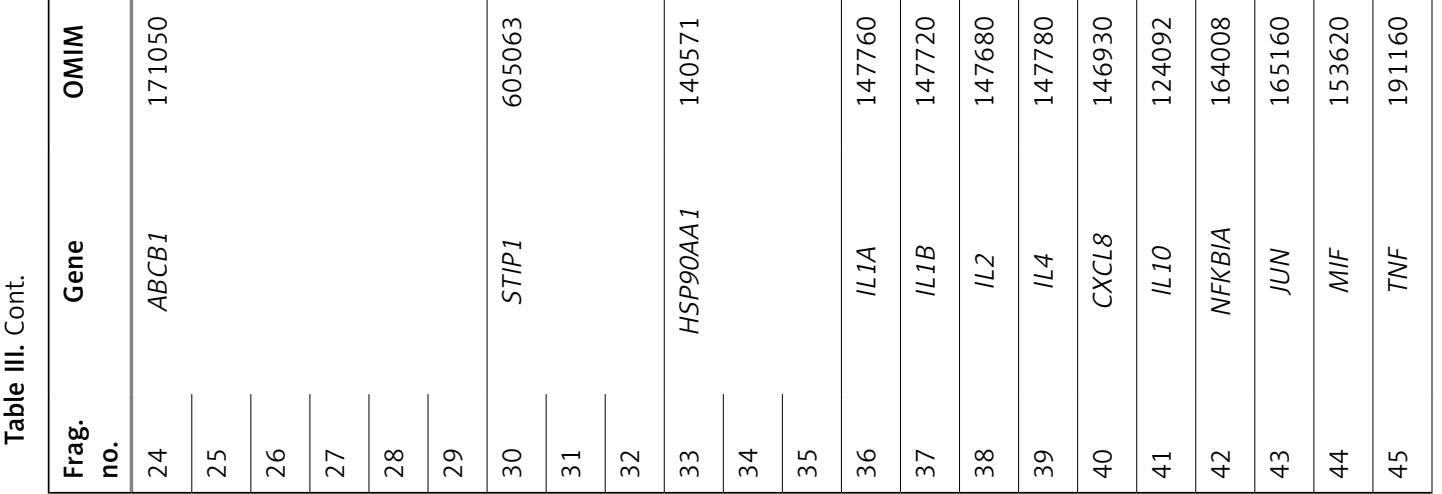




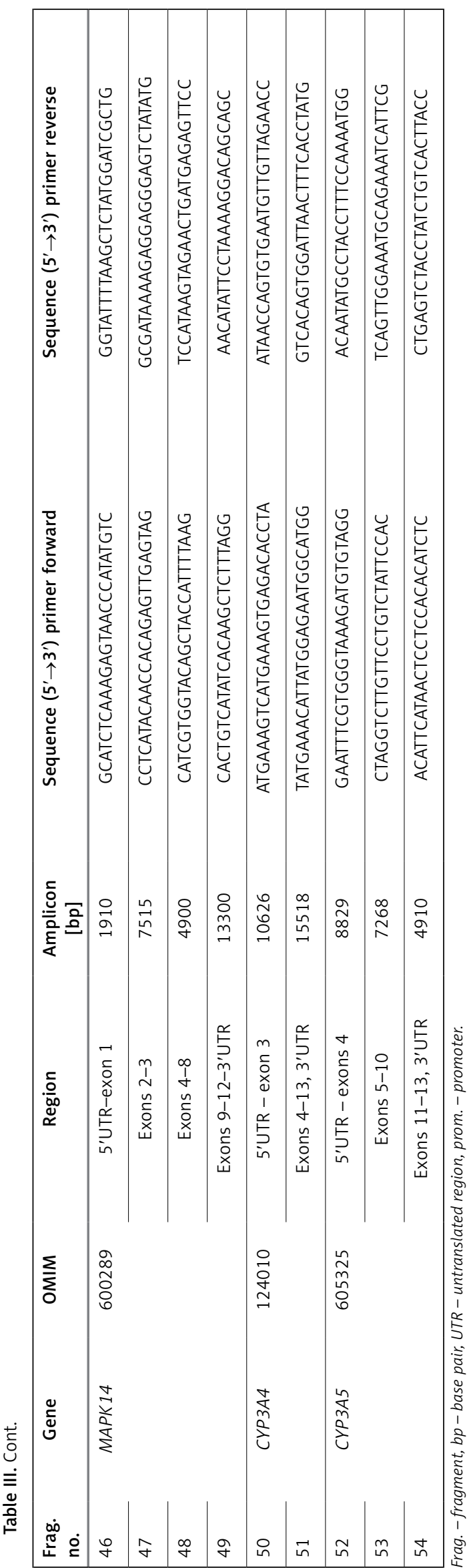

sponse and genetic variants (Table V), as well as analysis of clinical data in subgroups (Table II), were verified using the Pearson $\chi^{2}$ and Fisher tests with Bonferroni correction.

Statistical significance was set at $p \leq 0.05$. Bonferroni correction was applied for the number of study groups, but not for the number of analyzed loci. All calculations were performed using Statistica 12.0 software (Stat Soft, 2016).

\section{Results}

\section{Clinical outcome}

Our study group included 139 IBD patients, of whom $77(56 \%)$ reacted correctly to GC therapy and were classified as GC-sensitive, 24 (17\%) demonstrated resistance to treatment and 38 (27\%) were GC-dependent (Table I). The most frequently used GC drug was methylprednisolone in a dose above $24 \mathrm{mg} / 24 \mathrm{~h}$ (Table II). Correlation analysis of the treatment and drug dose with the response and gender did not reveal statistically significant differences ( $p=0.072, p=0.469$, respectively). There was a relationship between the treatment method and the diagnosis of CD and UC $(p<0.001)$. However, if budesonide was omitted, the significance disappeared ( $p=0.861$, Table II).

\section{LR-PCR and NGS results}

The target region of NR3C1, NLRP1, IPO13, FKBP5, HSPA4, ABCB1, STIP1, HSP9OAA1, IL-1A, IL-1B, IL-2, IL-4, CXCL8, IL-10, NFKBIA, JUN, MIF, TNF, MAPK14, CYP3A4, and CYP3A5 genes was amplified for each DNA sample in 54 fragments. The results of LR-PCR for one example DNA sample are presented in Figure 3. The NGS results obtained indicated on average $430 \pm 63$ SNVs per sample. Among 121 different functional DNA variants in the total group, for correlation analysis we selected 31 polymorphic variants in 14 genes (Table $V$ ), which occurred at a minor allele frequency (MAF) above 2\%. These have consequences for the protein structure and functionality based on VariantStudio 3.0 Software classification (Figures 1 and 4). Variants in the remaining studied 7 genes that were studied (IL-1B, IL-2, IL-10, IL-4, JUN, CYP3A4, IPO13) did not meet these selection criteria and were not qualified for further analysis. Moreover, in the literature described in response to the GCS context, the loci in the NR3C1 (c.1184+646C>G and p.Asn767Asn), $A B C B 1$ (c.2685+49T>C, p.Gly412Gly and p.lle1145Ile) and TNF (c.-308G >A and c.-238G>A) genes were also included [11]. The highest average number of NGS reads (above 400x) was observed for variants p.Cys13Ser (rs61745470) and p.Met71Leu (rs8005905) of the HSPA4 and HSP9OAA genes, respectively. The lowest coverage occurred for 
Table IV. Conditions of LR-PCR reactions

\begin{tabular}{|c|c|c|c|c|}
\hline Amplified fragments* & Reaction mixture & PCR program & & \\
\hline $\begin{array}{l}1,3-8,10-13,16,17 \\
20-23,25-29,31-41,45, \\
47,48,52-54\end{array}$ & $\begin{array}{c}38.4 \mathrm{ng} \text { template DNA } \\
0.48 \mu \mathrm{l} \text { of } 5 \mu \mathrm{mol} / \mathrm{l} \text { primers } \\
10 \mu \mathrm{l} \text { of GoTaq Master Mix } \\
\text { Water up to } 20 \mu \mathrm{l}\end{array}$ & $\begin{array}{l}95^{\circ} \mathrm{C}-2 \mathrm{~min} \\
94^{\circ} \mathrm{C}-30 \mathrm{~s} \\
65^{\circ} \mathrm{C}-1 \mathrm{~min} / \mathrm{kbp} \\
72^{\circ} \mathrm{C}-10 \mathrm{~min} \\
4^{\circ} \mathrm{C}-\infty\end{array}$ & $35 x$ & \\
\hline $9,24,50-51$ & $\begin{array}{c}50 \text { ng template DNA } \\
0.36 \mu \mathrm{l} \text { of a } 5 \mu \mathrm{mol} / \mathrm{l} \text { primers } \\
15 \mu \mathrm{l} \text { of GoTaq Master Mix } \\
\text { Water up to } 20 \mu \mathrm{l}\end{array}$ & $\begin{array}{l}95^{\circ} \mathrm{C}-2 \mathrm{~min} \\
94^{\circ} \mathrm{C}-30 \mathrm{~s} \\
65^{\circ} \mathrm{C}-1 \mathrm{~min} / \mathrm{kbp} \\
72^{\circ} \mathrm{C}-10 \mathrm{~min} \\
4^{\circ} \mathrm{C}-\infty\end{array}$ & $35 x$ & \\
\hline 18,19 & $\begin{array}{c}20 \mathrm{ng} \text { template DNA } \\
0.48 \mu \mathrm{l} \text { of a } 5 \mu \mathrm{mol} / \mathrm{l} \text { primers, } \\
4 \mu \mathrm{l} \text { of GC Enhancer } \\
10 \mu \mathrm{l} \text { of GoTaq Master Mix } \\
\text { Water up to } 20 \mu \mathrm{l}\end{array}$ & $\begin{array}{l}95^{\circ} \mathrm{C}-2 \mathrm{~min} \\
94^{\circ} \mathrm{C}-30 \mathrm{~s} \\
65^{\circ} \mathrm{C}-1 \mathrm{~min} / \mathrm{kbp} \\
72^{\circ} \mathrm{C}-10 \mathrm{~min} \\
4^{\circ} \mathrm{C}-\infty\end{array}$ & $35 x$ & \\
\hline 43,44 & $\begin{array}{c}38.4 \mathrm{ng} \text { template DNA } \\
0.48 \mu \mathrm{l} \text { of } 5 \mu \mathrm{mol} / \mathrm{l} \text { primers } \\
10 \mu \mathrm{l} \text { of GoTaq Master Mix } \\
\text { Water up to } 20 \mu \mathrm{l}\end{array}$ & $\begin{array}{l}95^{\circ} \mathrm{C}-2 \mathrm{~min} \\
94^{\circ} \mathrm{C}-30 \mathrm{~s} \\
55^{\circ} \mathrm{C}-30 \mathrm{~s} \\
65^{\circ} \mathrm{C}-1 \mathrm{~min} / \mathrm{kbp} \\
72^{\circ} \mathrm{C}-10 \mathrm{~min} \\
4^{\circ} \mathrm{C}-\infty\end{array}$ & $35 x$ & \\
\hline $2,14,15,30,42,46,49$ & $\begin{array}{c}20 \mathrm{ng} \text { template DNA } \\
0.48 \mu \mathrm{l} \text { of } 5 \mu \mathrm{mol} / / \text { primers, } \\
4 \mu \mathrm{l} \text { of GC Enhancer [Jena Bioscience] } \\
10 \mu \mathrm{l} \text { of GoTaq Master, } \\
\text { Water up to } 20 \mu \mathrm{l}\end{array}$ & $\begin{array}{l}95^{\circ} \mathrm{C}-2 \mathrm{~min} \\
94^{\circ} \mathrm{C}-30 \mathrm{~s} \\
65^{\circ} \mathrm{C}-30 \mathrm{~s}-1^{\circ} \mathrm{C} / \mathrm{cycle} \\
65^{\circ} \mathrm{C}-1 \mathrm{~min} / \mathrm{kbp} \\
94^{\circ} \mathrm{C}-30 \mathrm{~s} \\
50^{\circ} \mathrm{C}-30 \mathrm{~s} \\
65^{\circ} \mathrm{C}-1 \mathrm{~min} / \mathrm{kbp}+20 \\
72^{\circ} \mathrm{C}-10 \mathrm{~min} \\
4^{\circ} \mathrm{C}-\infty\end{array}$ & s/cycle & $25 \times$ \\
\hline
\end{tabular}

*The fragment numbers: 1-54 are identical with Table III and Figure 3.

the $A B C B 1$ gene changes $(22-65 x)$ (Table V). To verify the genotyping results obtained for this gene, we checked all five loci for the whole group of patients using the second method - Sanger sequencing. These data were overlapping. The SNVs were mostly in HWE. The exception concerned changes p.Val1059Met (rs2301582) and p.Met1184Val (rs11651270) in the NLRP1 gene, and p.Ser400Asn (rs2229109) in the $A B C B 1$ gene $(p<0.05$, Table $V)$. The allele frequencies identified and presented as MAF generally did not significantly differ from the European data (EU MAF) originating from the 1000 Genomes Project, except for the change p.Glu31Ter (rs188378669) in the CXCL8 gene, in which in contrast to the European population, the minor allele occurred eight times more often in our patient group (Table V).

\section{Correlation data}

In the first step, correlation analysis of obtained genotypes with a response to GC was performed in the whole group of 139 IBD patients (jointly all CD and UC cases). Only for the change $c .2685+49 T>C$ (rs2032583) in the $A B C B 1$ gene was an association with $G C$ reaction visible $(p=0.046)$. The presence of a substitution in position c.2685 correlated with the occurrence of resistance to GCs. Subsequently, the correlation analysis for two patient subgroups CD and UC was carried out, which demonstrated a statistically significant relationship in UC between GC response and the occurrence of the variants c.1088G $>A$ ( $r 556149945)$ in NR3C1 ( $p=0.019), c .241+6 A>G(r s 2817033)$ in the FKBP5 gene and c.306-7delT (rs61763106) in the MAPK 14 gene (Table V, Figure 5), while in $C D$, the change $C .2685+49 T>C($ rs2032583) in the $A B C B 1$ gene was relevant.

The allele $G$ in position c.1088 (rs56149945) of the NR3C1 gene was identified in UC in 1 patient with GC sensitivity (allele frequency: $1.35 \%$ ) compared to 3 patients heterozygous and 1 homozygous (allele frequency: 19.2\%) in the GC-resistant group. In patients with GC dependency allele G was not found (Figure 5). Consequently, subjects with genotype AG and homozygous GG showed significantly increased resistance to GCs compared to the rest of the patients with UC $(O R=21.333$, 95\% Cl: 2.130-213.648, $\left.\chi^{2}=11.44, p<0.001\right)$. The splicing variant c. $241+6 \mathrm{~A}>\mathrm{G}$ (rs2817033) in the FKBP5 gene was relevant to the $G C$ response 


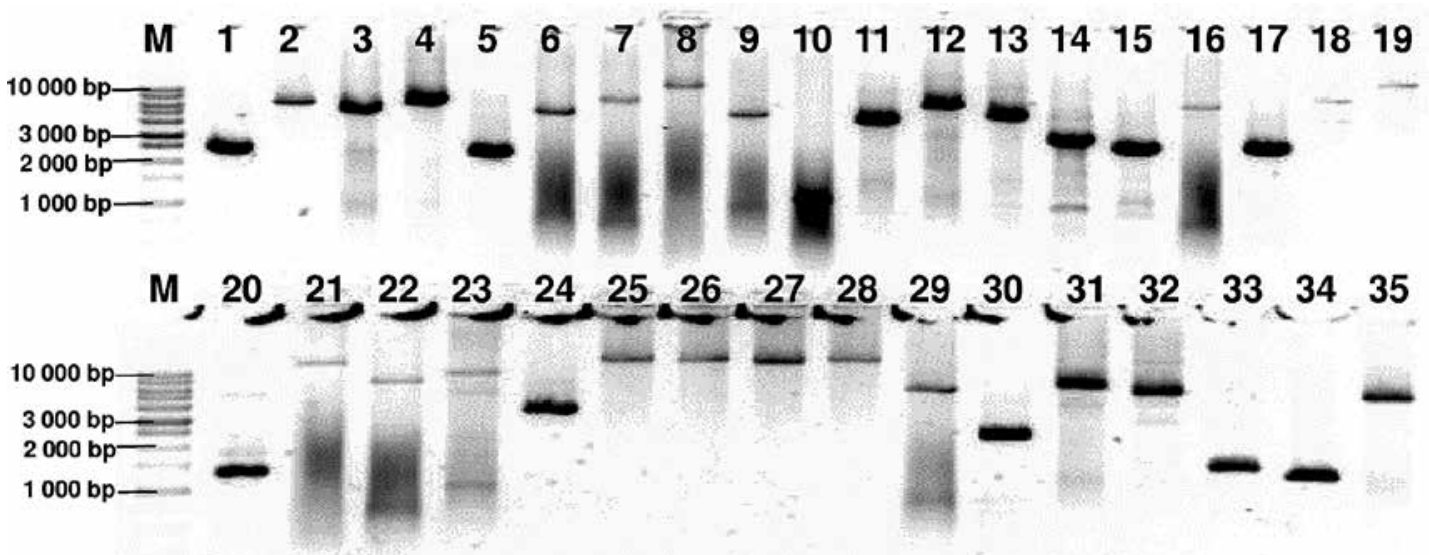

$\begin{array}{llllllllllllllllllll}M & 36 & 37 & 38 & 39 & 40 & 41 & 42 & 43 & 44 & 45 & 46 & 47 & 48 & 49 & 50 & 51 & 52 & 53 & 54\end{array}$

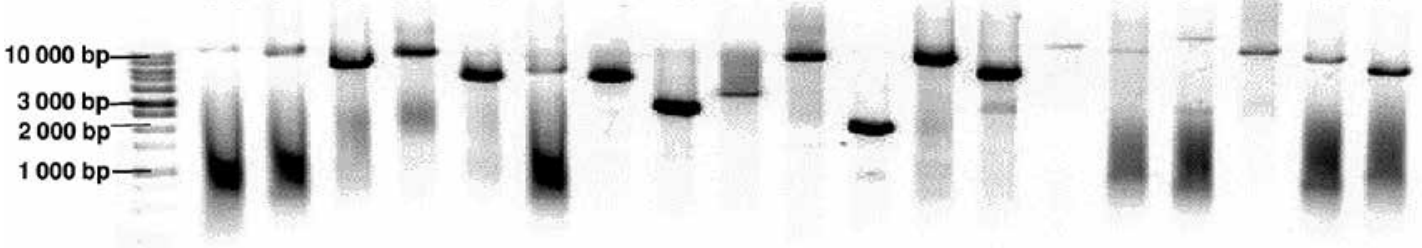

Figure 2. Agarose electrophoresis of all 54 LR-PCR products for one DNA sample. Lane: 1-5 NR3C1 (2400 bp, $6301 \mathrm{bp}$, 5031 bp, 6208 bp, 2261 bp), 6-10 - NLRP1 (5287 bp, 7575 bp, 12504 bp, 5023 bp, 1088 bp), 11-13 - IPO13 (4357 bp, 6294 bp, 4762 bp), 14-19 - FKBP5 (2935 bp, 2534 bp, 6516 bp, 2523 bp, 7518 bp, 12540 bp), 20-23 - HSPA4 (1290 bp, 13489 bp, 7051 bp, 9368 bp), 24-29 - ABCB1 (3518 bp, 15887 bp, 16809 bp, 14483 bp, 17000 bp, 5967 bp), 30-32 - STIP1 (2224 bp, 6456 bp, 5400 bp), 33-35 - HSP9OAA1 (1404 bp, 1238 bp, 5157 bp), 36 - IL1A (12577 bp), 37 - IL1B (10196 bp), 38 - IL2 (6505 bp), 39 - IL4 (10003 bp), 40 - CXCL8 (5000 bp), 41 - IL10 (6199 bp), 42 NFKBI (5016 bp), 43 - JUN (4730 bp), 44 - MIF (2731 bp), 45 - TNF (8831 bp), 46-49 - MAPK14 (1910 bp, 7515 bp, 4900 bp, 13300 bp), 50-51 - CYP3A4 (10626 bp, 15518 bp), 52-54 - CYP3A5 (8829 bp, 7268 bp, 4910 bp), $1 \mathrm{~kb}$ - marker ladder $1000 \mathrm{bp}$. The gel images were obtained by trimming and color adjusting of the full-length gels in the IrfanView 4.44 program. The lanes numbering corresponds with the numbering of the amplified fragments in Tables III and IV

when comparing the GC-sensitive group versus the rest of UC patients ( $p=0.040$, Table $V$ ). The frequency of the $\mathrm{G}$ allele was $62.2 \%$ in the GC-sensitive group, $58.3 \%$ in -dependent and $42.3 \%$ in -resistant. However, the substitution c. $241+6 \mathrm{~A}>\mathrm{G}$ inversely correlates with the response to GCs. The homozygous $A A$ is significantly more frequent than $A G+G G$ genotypes in the GC-sensitive group compared to the rest of the UC patients $(\mathrm{OR}=0.188$, $95 \% \mathrm{Cl}: 0.044-0.799, \chi^{2}=5.84, p=0.016$, Figure 5).

We also observed that the variant c.306-7delT in the MAPK 14 gene $(p=0.040)$ has an effect on GC sensitivity. The allele with deletion $T$ in position c.306-7 was found in UC with a frequency of $4.05 \%$ in the GC-sensitive group, $16.7 \%$ in the GC-dependent and $19.2 \%$ in the GC-resistant group. Deletion T carriers and homozygotes with a mutation showed significant increased dependency or resistance to therapy compared to GC-sensitive patients with UC $(\mathrm{OR}=9.722$, 95\% Cl: $1.922-49.183, \chi^{2}=9.73, p=0.002$ ).

In $C D$ patients, only one substitution, c. $2685+49 T>C$ in the $A B C B 1$ gene, has an impact on resistance to GCs $(p=0.034)$, which was also visible in the whole group of 139 IBD patients $(p=0.046)$. The changed allele $C$ was indicated in 11 (17.3\%) GC-sensitive and 9 (13.6\%) GC-dependent patients. In patients with GC resistance, this allele was absent. The results show that allele $C$ causes a protective effect on $\mathrm{GC}$ resistance (Figure 5 ). The genotype TC demonstrated significantly lower frequency versus TT in GC-resistant patients compared to rest of the CD patients $(\mathrm{OR}=0.099$ 95\% Cl: 0.006-1.755, $\chi^{2}=4.50, p=0.034$ ).

\section{Discussion}

Pharmacogenetics in IBD is the subject of a significant amount of research, which consistently concludes that there is a lack of sufficiently strong biomarkers for GC therapy that are useful in clinical practice, thus emphasizing the need for further research $[7,14,17]$. Although the mechanism of GC action involves dozens of genes, so far intensive pharmacogenetic studies of these drugs have focused mainly on single genes, and have produced contradictory results. An example is the $N R 3 C 1$ gene, of which the $c .1184+646 C>G$ polymorphism shows the effect with the $G C$ response $[14,22]$, although there is a study which does not confirm this observation $[16,23]$. 
Considering the action, transport and metabolism of GCs, in our research we decided to expand significantly the number of genes studied to include both frequently tested $N R 3 C 1$ for GR and transporter $A B C B 1$ and cytokine genes IL-1A, IL1B, IL-2, IL-4, CXCL8, IL-10, TNF, chaperones and co-chaperones HSP90AA1, HSPA4, STIP1, FKBP5, inflammasome activator NLRP1, kinase MAPK14, transcription factor genes $J U N$ and NFKBIA, the macrophage migration inhibitory factor MIF gene, metabolism enzyme genes CYP3A4 and CYP3A5, and the importin gene IPO13. The most important purpose of the present study was to determine whether the consequence of genetic variants of the 21 genes selected affect the GC response by studying a cohort of 139 Polish adult IBD patients treated with methylprednisolone, hydrocortisone and slight budesonide (Table II). It was also examined whether the GC treatment depends on gender and diagnosis of CD or UC and whether it affects the $\mathrm{GC}$ response in IBD patients because different treatment strategies, i.e. oral methylprednisolone, intravenous hydrocortisone, and oral budesonide, could create a severe limitation (Table II). It is also worth emphasizing that the bioavailability and hepatic activity of budesonide differ from methylprednisolone and hydrocortisone. At the same time, budesonide is dedicated primarily to a specific form of CD. According to ECCO guidelines, it should be effective in patients with ileocaecal localization of CD [1]. We have found no connection between the method of GC therapy and response to it. The GC drugs used in our studies were similar to those investigated in earlier pharmacogenetic research on patients with IBD conducted by Krupoves et al., who evaluated prednisolone and budesonide [24, 25]. Gender also showed no effect on the response to the GCs, but we did identify a significant difference in treatment between patients with CD and UC. However, oral treatment with budesonide during this study was dedicated in Poland only to patients with CD. Therefore, the UC patients could not receive it, which led to differences in GC treatment in our CD and UC patient groups.

High-throughput NGS technology was very helpful in achieving our molecular genetics aim. Therefore, as an additional goal of this work, we developed a rapid, flexible and economical application of NGS by combining it with LR-PCR as target enrichment for pharmacogenetic studies on GC drugs. A similar solution was used successfully in earlier studies $[19,20]$. In bioinformatic analysis for our scientific purposes, in contrast to diagnostic standards of minimum coverage $30 \times$ [26], we carefully applied a reads cover filter of 10 to avoid omission of any variants at this stage (Figure 2). For most of the loci, the mean coverage for each position analyzed was higher than the cut-off

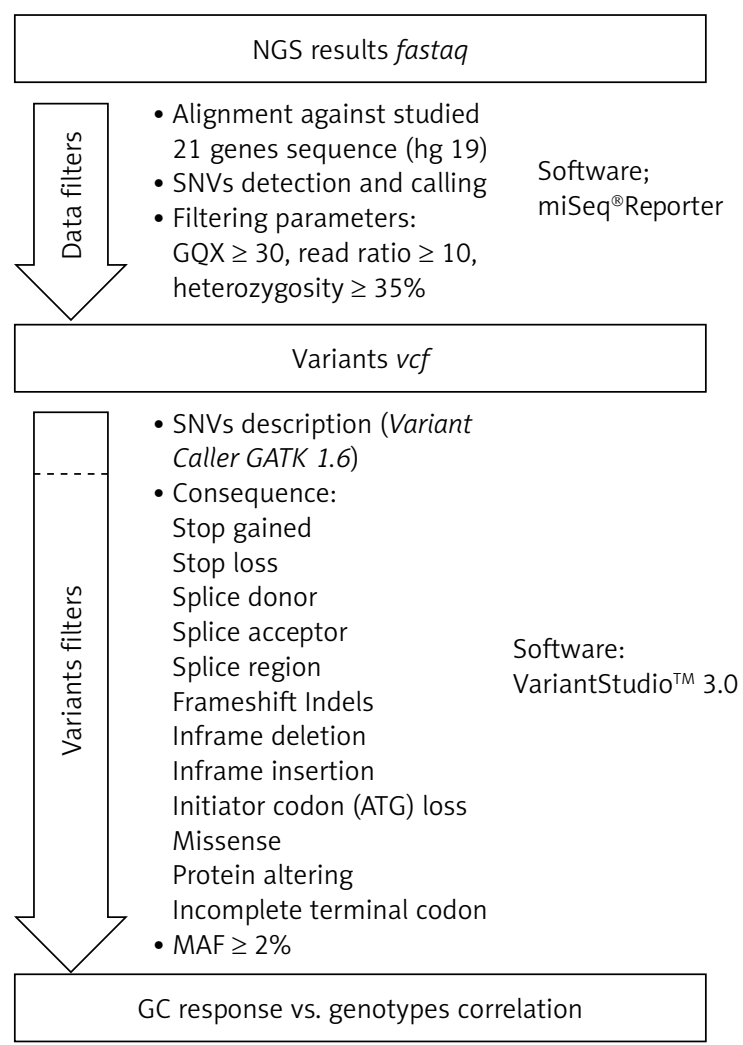

Figure 3. The pipeline of NGS results analysis and variant selection

SNVS - single nucleotide variants, GQX - genotyping quality, MAF-minor allele frequency.

value, i.e. between 22 and 435 (Table V). When it was below 30x, we verified the genotyping data. The weak point of this method turned out to be only the $A B C B 1$ gene. Therefore, for all changes selected for this gene, we performed a full verification for all patients. In the future, the input of the $A B C B 1$ gene amplicons can be increased in the whole library to improve the results. It must be pointed out, however, that the LR-PCR NGS method we applied is easy to modify and relatively cheap. Our calculations including reagents and materials show that LR-PCR NGS would be at least seven times less expensive and laborious than Sanger sequencing [20].

The results of sequence analysis with a total length of $376894 \mathrm{~kb}$ per patient showed the presence of an average of 430 changes per sample, 31 of which were selected for statistical analysis, and finally 4 significantly associated with the response to GCs (Figure 4). These variants include p.Asn363Ser in NR3C1, c.241+6A>G in the FKBP5, c.306-7delT in the MAPK 14 and c.2685+49T>C in the $A B C B 1$ gene. Most of the changes investigated in the context of the $G C$ response in IBD refer to the $N R 3 C 1$ and $A B C B 1$ genes (Table V). The NR3C1 gene variants have been related to both $G C$ sensitivity and resistance $[14,24,27,28]$, while $A B C B 1$ variants, leading to decreased activity of trans- 


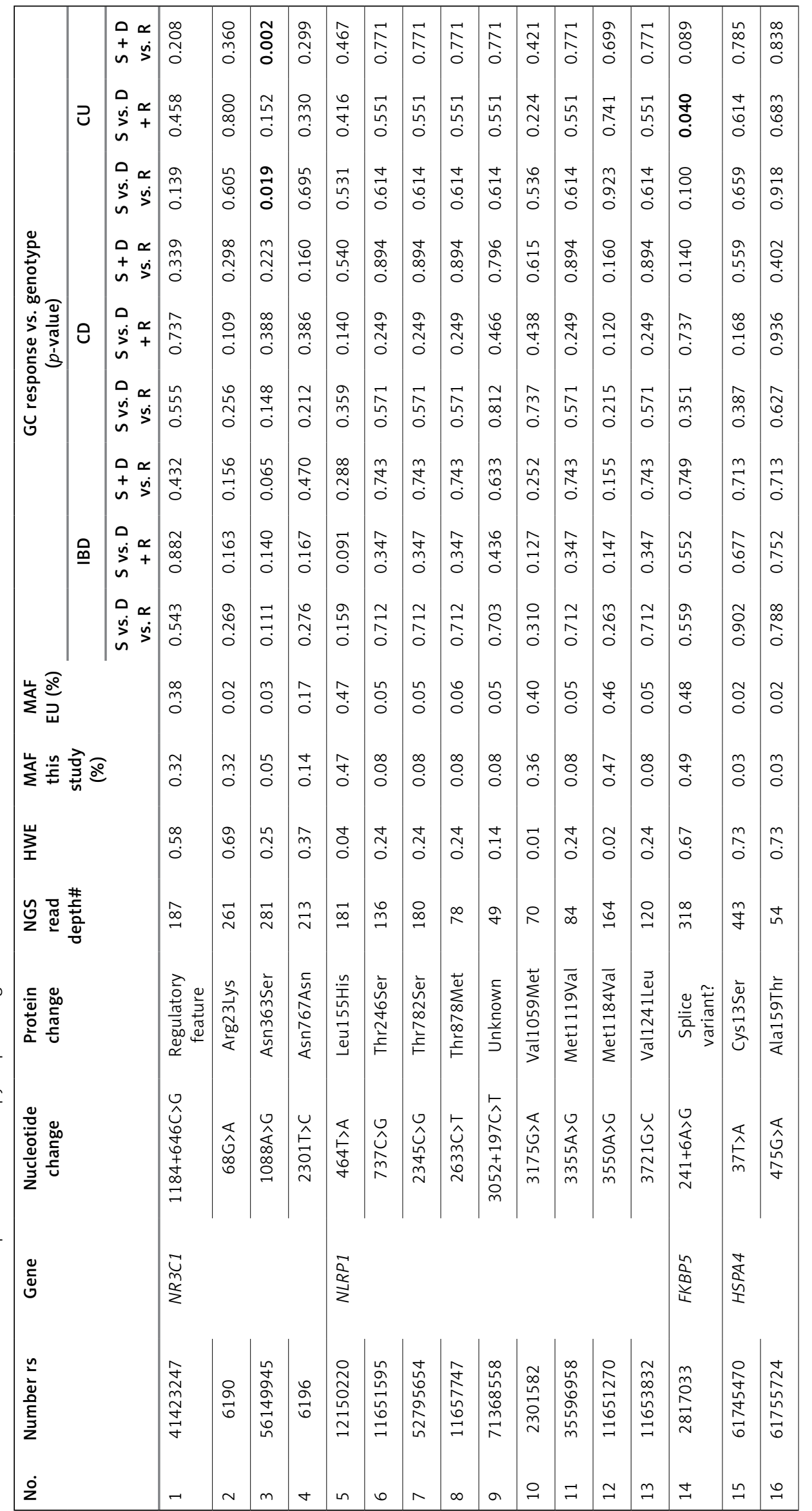




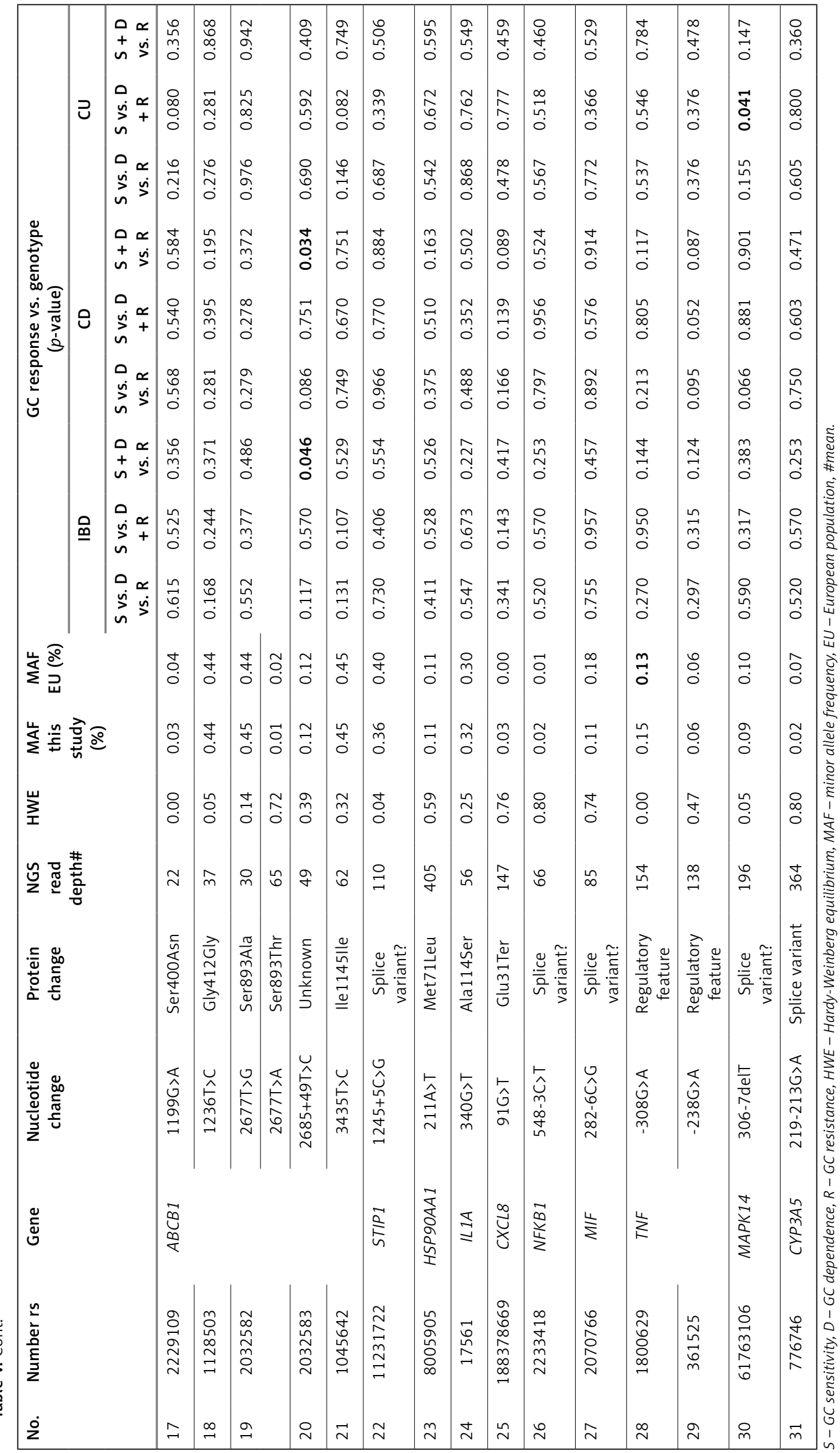




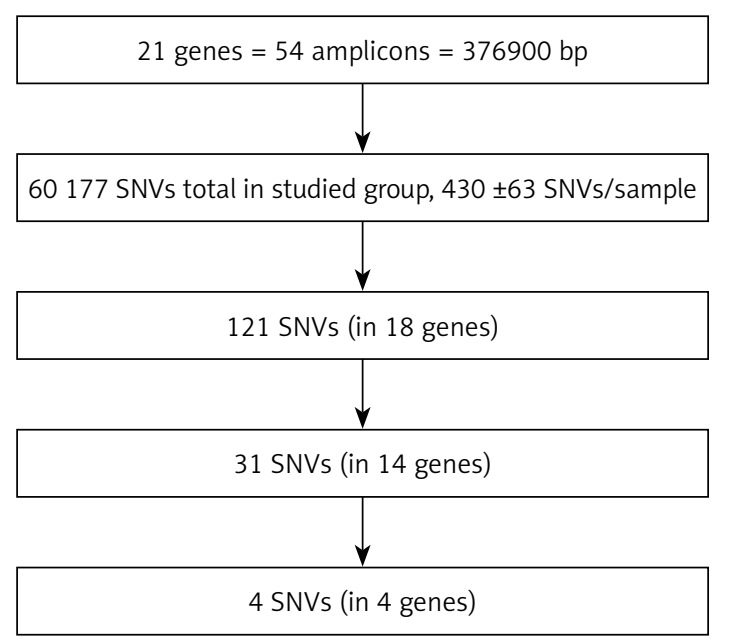

Analyzed DNA sequence per sample

Detected SNVs

Consequence SNVS

Consequence SNVs, MAF $\geq 2 \%$

SNVs correletd with GCs response

Figure 4. Flow diagram of genetic variant selection steps

SNVs - single nucleotide variants, bp - base pair, SD - standard deviation, MAF-minor allele frequency.

A

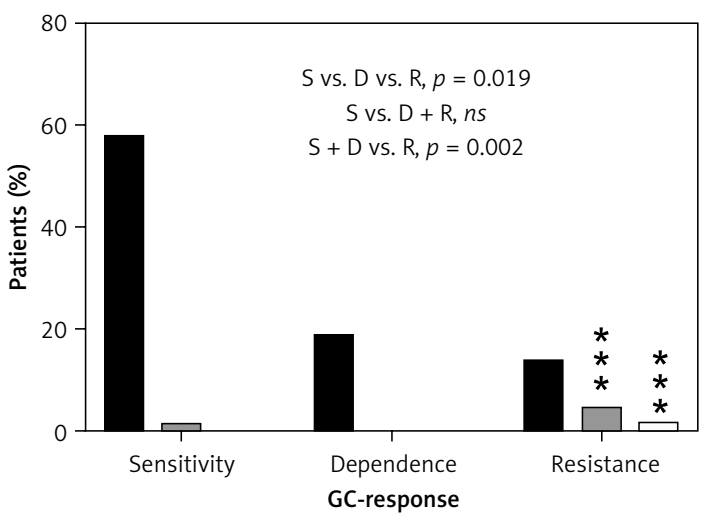

- AA $\square$ AG $\square$ GG

c

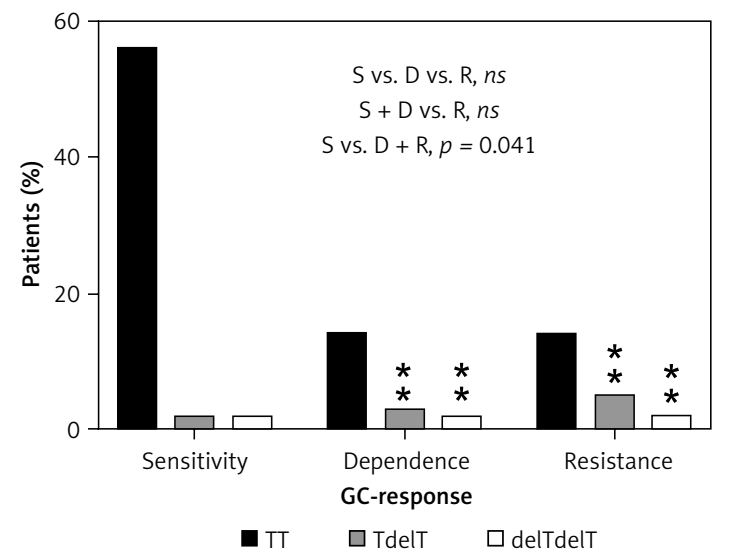

B

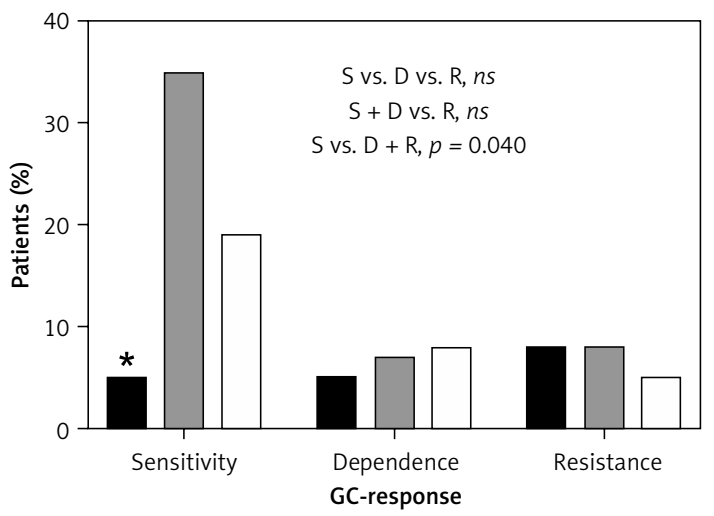

- AA $\square$ AG $\square G G$

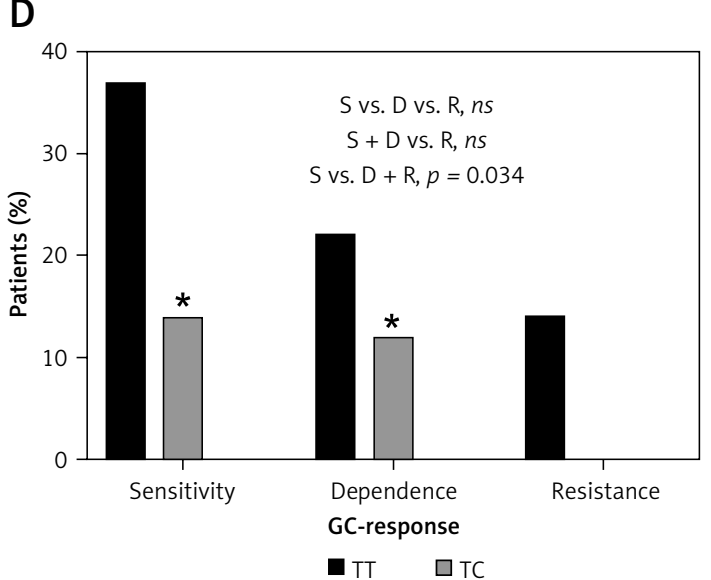

Figure 5. Distribution of genotypes for significantly correlated variants: $A-N R 3 C 1$, c.1088A>G, UC patients, B - FKBP5, c.241+6A>G, UC patients, C - MAPK14, c.306-7delT, UC patients, D - ABCB 1, C.2685+49T>C, CD patients ns - non-significant, " relevant genotypes for the GC-response type, $p<0.05,{ }^{* *} p<0.01,{ }^{* * *} p<0.001$.

porter protein, were associated with GC dependence $[25,29]$. Previous studies on pediatric IBD patients showed the significance of substitution c. $1184+646 C>G$, leading to increased sensitivity in $\mathrm{GC}$ responders versus dependents [14, 22].
Krupoves et al. demonstrated exonic changes p.Arg23Lys and p.Asn767Asn of the NR3C1 gene in pediatric $C D$ in association with $G C$ resistance [24]. Our investigation does not confirm this outcome and is consistent with studies conducted 
on a group of 200 Caucasians with IBD, where the researchers did not find any association [16]. In our observation, only variant p.Asn363Ser in the NR3C1 gene, which results in the amino acid change from asparagine to serine in codon 363 in the N-terminal trans-activation domain of the GR protein, revealed a significant difference in genotype distribution in the GC-sensitive, -dependent and -resistant groups ( $p=0.019)$. The genotype AG and homozygous GG correlate with increased resistance to GCs compared to the rest of the UC patients, but not CD subjects (Figure 5). In contrast, independent studies have shown no association between the p.Asn363Ser change and the response to $G C$ therapy $[14,16,23,24]$. There is only evidence that this substitution influences increased sensitivity for exogenous GCs. Huizenga et al. demonstrated stronger inhibition of lymphocyte proliferation by exogenous dexamethasone in heterozygous AG than in wild-type patients. Carriers of the $G$ allele were characterized by a higher $\mathrm{BMI}$ index and higher insulin level in blood after the administration of dexamethasone [30].

In previous research on $A B C B 1$ gene variants, Annese et al. found no association between p.Ser893Ala (rs2032582) and p.lle1145lle (rs1045642) polymorphisms and for the response to GC treatment. They investigated a group of 594 patients with IBD treated with GCS and a control group of 450 healthy people [31]. The same observation was made by Cucchiara et al. in their research on groups of 200 children with CD and 186 children with UC [15]. However, in contrast to those data, in a Chinese population among three studied variants c.2677T>G, c.1236C>T (p.Gly412Gly, rs1128503), and c.3435C $>T$ of the $A B C B 1$ gene, the CC genotypes in positions C.1236 and C.3435 were more frequent in GC-dependent CD patients than in those responsive to GC, showing that the CC homozygosity of the two SNPs might be the risk factor for GC dependence in CD [29]. Furthermore, Canadian researchers demonstrated a significant association between the polymorphism 2685+49T>C (rs2032583) and the haplotype C-T-C for changes C.3435C $>\mathrm{T}, \mathrm{C} .117+4196 \mathrm{~T}>\mathrm{C}$ (rs3789243) and $2685+49 T>C$ with the occurrence of GC dependence in 260 juvenile patients with $C D$ [25]. They found that in position c.2685+49 in the $A B C B 1$ gene the allele $C$ and genotype $C T$ are protective for dependency on $\mathrm{GC}$ treatment, ( $p=0.029$ and $p=0.035$, respectively) [25]. This observation is partly consistent with our results. After correlation analysis of five SNVS c.3435C >T, c.2677T>G, c.1236C >T, c.2685+49T>C and c.1199G >A (p.Ser400Asn, rs2229109) - in the $A B C B 1$ gene, we found an inverse association of $c .2685+49 T>C$ with $G C$ resistance $(p=0.034)$. We confirm the protective function of the $C$ allele by GC-sensitive and -dependent patients against
GC-resistant patients with CD. For the other four $A B C B 1$ variants, we did not observe any significant changes in the frequency of genotypes in particular GC groups.

In these studies, we also identified two associations in loci which were not described earlier in the context of GC treatment and they are not reported in the ClinVar database (https://www. ncbi.nlm.nih.gov/clinvar/). We found that the splicing variants c. $241+6 \mathrm{~A}>\mathrm{G}$ in the FKBP5 and c.306-7delT in the MAPK14 gene were relevant in GCs' response comparing the GC-sensitive group versus the rest of the UC patients ( $p=0.040$ and $p=0.041$, respectively). Until now, only studies by Italian scientists exist in this area, which demonstrated the influence of a putative promoter variant C. $-20+18122 T>C$ (rs4713916) in the FKBP5 gene on $G C$ sensitivity in patients with $C D$ but not in UC [16]. The FKBP-51 protein is critical in the correct binding of GCs to GR and in transporting $G R$ to the cell nucleus. Maltese et al. explain that increased expression of FKBP-51 leads to the decreased ability of GR- $\alpha$ to bind GCS, but also to increased translocation of the nonactive GR- $\beta$ isoform to the cell nucleus [16, 32]. We found that the wildtype homozygous AA in position c. $241+6$ is significantly rarer than $A G+G G$ genotypes in GC-sensitive patients compared to the rest of the UC patients. Surprisingly, this would indicate that change promotes sensitivity to treatment, which may be related to the maintenance of optimal proportions in the binding of FKBP-51 protein to the active and non-active isoform of the GR. Therefore, we postulate that a splicing variant of the FKBP 5 gene observed in our studies could change the level of functional FKBP-51 protein or modify it, and contribute to the emergence of higher GC sensitivity. However, this issue requires further functional research.

The last significant variant in our studies, c.3067delT, is located in the intron 3 acceptor region of the MAPK 14 gene coding for mitogen-activated protein kinase 14 , which is also known as MAP kinase p38 $\alpha$. We found a correlation between carriers of $\mathrm{T}$ deletion and homozygous mutants and increased GC dependency or resistance compared to $G C$ sensitivity in patients with UC (OR $=9.722$, $p=0.002)$. MAP kinase $p 38$, which is activated by IL2 and IL-4, phosphorylates GR, resulting in the inhibition of its transcriptional activity [33]. GCs reduce the MAPK signaling pathway via the induction of MAPK phosphatase 1 (MKP1), which consequently inhibits the expression of different inflammatory genes [34]. Furthermore, Bhavsar et al. have proved in severe asthma patients that GC resistance may be improved by inhibitors of p38 MAPK [35]. Accordingly, we suppose that the intronic variant c.306-7delT of the MAPK 14 gene relevant in our study could lead to the creation of 
an altered protein variant, which may not be efficiently inhibited by MKP1 and consequently GC resistance and dependence occurs [12].

In the literature, DNA variants are described, i.e., p.Leu155His (rs12150220) in the NLRP1 gene [14], and c.-308G>A (rs1800629) in the TNF gene $[15,36]$, related to the response to GCs. We have not confirmed these observations in our studies. Moreover, our results showed apparent differences in the associations of variants between CD and UC that were analyzed. These immunological disorders, although belonging to one group, IBD, are two different diseases with as yet unclear etiology, a different genetic background and probably different pharmacogenetics [16, 37].

It is worth emphasizing that the NGS results obtained seem to have further potential due to the remaining untranslated regions (UTRs), promoters and intron variants which, according to our assumptions, we essentially filtered out. Thus, in the next step, we are planning to correlate these SNVs with clinical data concerning the GC effect. The especially high importance of non-exonic variants was proved by de ludicibus et al. in recent research, because of binding sites for microRNA [38]. Moreover, it should be taken into account that for personalized glucocorticoid treatment in IBD, a comprehensive approach integrating both genome and transcriptome research, including coding and non-coding RNA, will be necessary [39].

We are aware of the limited subjects of our study group. Therefore, explaining the functional effect of the variants being analyzed will be of particular importance and the present results might become part of the meta-analyses, which will bring us closer to selecting biomarkers for predicting and individualizing GC treatment.

In conclusion, our results demonstrate the critical role of genetic factors of various genes such as FKBP5 and MAPK 14 in the response of IBD patients to GC treatment, which indicates the complex contribution of low penetration genes in the GC response. Moreover, we observed that the genetic background differs between CD and UC. Our results should be confirmed in studies on different populations and further functional investigation.

\section{Conflict of interest}

Marcin Gabryel is a recipient of a fellowship for a young researcher from Poznan Medical University (Poland, grant no. 502-14-02223359-41103) and from the Polish National Science Centre (grant no. 2015/17/N/N25/00689). Other authors declare no conflict of interest.

\section{References}

1. Gomollón F, Dignass A, Annese V, et al. $3^{\text {rd }}$ European evidence-based consensus on the diagnosis and man- agement of Crohn's disease 2016: Part 1: diagnosis and medical management. J Crohns Colitis 2017; 11: 3-25.

2. Harbord M, Eliakim R, Bettenworth D, et al. Third European evidence-based consensus on diagnosis and management of ulcerative colitis part 2: current management. J Crohns Colitis 2017; 11: 769-84.

3. Derijks LJJ, Wong DR, Hommes DW, et al. Clinical pharmacokinetic and pharmacodynamic considerations in the treatment of inflammatory bowel disease. Clin Pharmacokinet 2018; 57: 1075-106.

4. De ludicibus S, Franca R, Martelossi S, et al. Molecular mechanism of glucocorticoid resistance in inflammatory bowel disease. World J Gastroenterol 2011; 17: 1095-108.

5. Barnes PJ, Adcock IM. Glucocorticoid resistance in inflammatory diseases. Lancet 2009; 30: 1905-17.

6. Farrell RJ, Kelleher D. Glucocorticoid resistance in inflammatory bowel disease. J Endocrinol 2003; 178: 339-46.

7. Lucafò M, Franca R, Selvestrel D, et al. Pharmacogenetics of treatments for inflammatory bowel disease. Expert Opin Drug Metab Toxicol 2018; 14: 1209-23.

8. Vermeire S, Van Assche G, Rutgeerts P. Role of genetics in prediction of disease course and response to therapy. World J Gastroenterol 2010; 16: 2609-15.

9. Pierik M, Rutgeerts P, Vlietinck R, et al. Pharmacogenetics in inflammatory bowel disease. World J Gastroenterol 2006; 12: 3657-67.

10. Evans WE, McLeod HL. Pharmacogenomics-drug disposition, drug targets, and side effects. N Engl J Med 2003; 348: 538-49.

11. Gabryel M, Skrzypczak-Zielinska M, Kucharski MA, et al. The impact of genetic factors on response to glucocorticoids therapy in IBD. Scand J Gastroenterol 2016; 51: 654-65.

12. Barnes PJ, Adcock IM. Glucocorticoid resistance in inflammatory diseases. Lancet 2009; 373: 1905-17.

13. Rufini S, Ciccacci C, Novelli G, et al. Pharmacogenetics of inflammatory bowel disease: a focus on Crohn's disease. Pharmacogenomics 2017; 18: 1095-114.

14. De ludicibus S, Stocco G, Martelossi S, et al. Genetic predictors of glucocorticoid response in pediatric patients with inflammatory bowel diseases. J Clin Gastroenterol 2011a; 45: 1-7.

15. Cucchiara S, Latiano A, Palmieri O, et al. Polymorphisms of tumor necrosis factor-alpha but not MDR1 influence response to medical therapy in pediatric-onset inflammatory bowel disease. J Pediatr Gastroenterol Nutr 2007; 44: 171-9.

16. Maltese P, Palma L, Sfara C, et al. Glucocorticoid resistance in Crohn's disease and ulcerative colitis: an association study investigating GR and FKBP5 gene polymorphisms. Pharmacogenomics J 2012; 12: 432-8.

17. Newton R. Molecular mechanisms of glucocorticoid action: what is important? Thorax 2000; 55: 603-13.

18. Satsangi J, Silverberg MS, Vermeire S, Colombel JF. The Montreal classification of inflammatory bowel disease: controversies, consensus, and implications. Gut 2006; 55: 749-53.

19. Zakerska-Banaszak O, Skrzypczak-Zielinska M, Tamowicz B, et al. Longrange PCR-based next-generation sequencing in pharmacokinetics and pharmacodynamics study of propofol among patients under general anaesthesia. Sci Rep 2017; 7: 15399.

20. Walczak M, Skrzypczak-Zielinska M, Plucinska M, et al. Long-range PCR libraries and next-generation sequencing for pharmacogenetic studies of patients treated with anti-TNF drugs. Pharmacogenomics J 2018; doi: 10.1038/s41397-018-0058-9 [Epub ahead of print]. 
21. Yamamoto-Furusho JK. Pharmacogenetics in inflammatory bowel disease: understanding treatment response and personalizing therapeutic strategies. Pharmgenomics Pers Med 2017; 10: 197-204.

22. De ludicibus S, Stocco G, Martelossi S, et al. Association of Bcll polymorphism of the glucocorticoid receptor gene locus with response to glucocorticoids in inflammatory bowel disease. Gut 2007; 56: 1319-20.

23. Mwinyi J, Wenger C, Eloranta JJ, et al. Glucocorticoid receptor gene haplotype structure and steroid therapy outcome in IBD patients. World J Gastroenterol 2010; 16: 3888-96.

24. Krupoves A, Mack D, Deslandres C, et al. Variation in the glucocorticoid receptor gene (NR3C1) may be associated with corticosteroid dependency and resistance in children with Crohn's disease. Pharmacogenet Genomics 2011; 21: 454-60.

25. Krupoves A, Mack D, Seidman E, et al. Associations between variants in the ABCB1 (MDR1) gene and corticosteroid dependence in children with Crohn's disease. Inflamm Bowel Dis 2011; 17: 2308-17.

26. Mu W, Lu HM, Chen J, et al. Sanger confirmation is required to achieve optimal sensitivity and specificity in next generation sequencing panel testing. J Mol Diagn 2016; 18: 923-32.

27. Gross KL, Lu NZ, Cidlowski JA. Molecular mechanisms regulating glucocorticoid sensitivity and resistance. Mol Cell Endocrinol 2009; 300: 7-16.

28. Chen HL, Li LR. Glucocorticoid receptor gene polymorphisms and glucocorticoid resistance in inflammatory bowel disease: a meta-analysis. Dig Dis Sci 2012; 57: 3065-75.

29. Yang QF, Chen BL, Zhang QS, et al. Contribution of MDR1 gene polymorphisms on IBD predisposition and response to glucocorticoids in IBD in a Chinese population. J Dig Dis 2015; 16: 22-30.

30. Huizenga NA, Koper JW, De Lange P, et al. A polymorphism in the glucocorticoid receptor gene may be asso ciated with and increased sensitivity to glucocorticoids in vivo. J Clin Endocrinol Metab 1998; 83: 144-51.

31. Annese V, Valvano MR, Palmieri O, et al. Multidrug resistance 1 gene in inflammatory bowel disease: a metaanalysis. World J Gastroenterol 2006; 12: 3636-44.

32. Zhang X, Clark AF, Yorio T. FK506-binding protein 51 regulates nuclear transport of the glucocorticoid receptor beta and glucocorticoid responsiveness. Invest Ophthalmol Vis Sci 2008; 49: 1037-47.

33. Irusen E, Matthews JG, Takahashi A, et al. p38 Mitogen-activated protein kinase-induced glucocorticoid receptor phosphorylation reduces its activity: role in steroid-insensitive asthma. J Allergy Clin Immunol 2002; 109: 649-57.

34. Clark AR. MAP kinase phosphatase 1: a novel mediator of biological effects of glucocorticoids? J Endocrino 2003; 178: 5-12.

35. Bhavsar P, Khorasani N, Hew M, et al. Effect of p38 MAPK inhibition on corticosteroid suppression of cytokine release in severe asthma. Eur Respir J 2010; 35: 750-6.

36. Louis E, Peeters M, Franchimont D, et al. Tumour necrosis factor (TNF) gene polymorphism in Crohn's disease (CD): influence on disease behaviour? Clin Exp Immunol 2000; 119: 64-8.

37. Wędrychowicz A, Tomasik P, Zając A, Fyderek K. Prognostic value of assessment of stool and serum IL-1beta, IL-1ra and IL- 6 concentrations in children with active and inactive ulcerative colitis. Arch Med Sci 2018; 14 107-14.
38. De ludicibus S, Lucafò M, Vitulo N, et al. High-throughput sequencing of microRNAs in glucocorticoid sensitive paediatric inflammatory bowel disease patients. Int J Mol Sci 2018; 19: E1399.

39. Lucafò M, Stankovic B, Kotur N, et al. Pharmacotranscriptomic biomarkers in glucocorticoid treatment of pediatric inflammatory bowel disease. Curr Med Chem 2018; 25: 2855-71. 